\title{
A preoperative checklist in esthetic plastic surgery
}

\author{
Um checklist pré-operatório em cirurgia plástica estética
}

\author{
Jaime ANGER ${ }^{1}$ \\ NeLSON Letizio ${ }^{2}$ \\ Maurício OReL ${ }^{2}$ \\ José Leão de SOUZa Junior ${ }^{3}$ \\ MárCio Martines dos \\ SANTOS $^{4}$
}

Study conducted at Hospital Israelita Albert Einstein, São Paulo, SP, Brazil.

Submitted to SGP (Sistema de Gestão de Publicações/Manager Publications System) of RBCP (Revista Brasileira de Cirurgia

Plástica/Brazilian Journal of Plastic Surgery)

Received: January 13, 2011 Accepted: February 21, 2011

\begin{abstract}
The authors present a checklist to be used at the last stage of a preoperative visit for esthetic plastic surgery composed of 29 yes/no questions, four blank spaces for entering data, and one question for ranking the level of risk of deep vein thrombosis. The criteria are divided into three tables relating to three areas: anesthesia, psychological aspects, and clinical risk factors. The answers are framed in four colors that identify the level of risk and suggest the degree of attention warranted. A fourth aggregate table contains reference sources which can be easily accessed during a medical visit via the Internet or a portable device equipped with a medical database software. The purpose of the checklist is to reduce the possibility of adverse events involving the surgical process by identifying the risk level of each item reviewed.
\end{abstract}

Keywords: Checklist. Plastic surgery. Preoperative care. Intraoperative complications/ prevention \& control. Postoperative complications/prevention \& control.

\section{RESUMO}

Os autores apresentam um checklist para ser utilizado na última etapa da consulta préoperatória de cirurgias plásticas estéticas, composto de 29 perguntas, com respostas do tipo sim e não, quatro espaços para inserção de dados e uma questão para classificação do nível de risco em trombose venosa profunda. Os quesitos são divididos em três tabelas relativas a três áreas: anestesia, aspectos psicológicos e riscos clínicos. As respostas são enquadradas em quatro cores, que identificam o nível de risco e sugerem o grau de atenção. Uma quarta tabela agregada contém fontes de referência de fácil acesso durante a consulta médica, pela Internet ou por aparelhos portáteis que contenham programas de dados que forneçam informações sobre medicações ou afecções. A finalidade do checklist é diminuir a possibilidade de ocorrências indesejáveis que envolvam o processo cirúrgico, pela identificação do nível de risco de cada item revisto.

Descritores: Lista de checagem. Cirurgia plástica. Cuidados pré-operatórios. Complicações intra-operatórias/prevenção \& controle. Complicações pós-operatórias/prevenção \& controle.

\section{INTRODUCTION}

In recent years, technological and scientific advances, especially advances in the media for information delivery, have enabled the accumulation of vast stores of medical information. The training of physicians has become longer and more intense. In esthetic plastic surgery, the proliferation of scientific discoveries and the exchange of knowledge have led to advances in surgical technique and greater specialization amongst physicians. As esthetic surgical procedures have grown more popular and more accessible to patients, more plastic surgeries are being performed. Though this situation has contributed to the emergence of a number of professionals with extraordinary ability, undesirable outcomes, some of them infuriating and demoralizing, persist.

Therefore, there is a need for strategies to identify oversights that could lead to avoidable complications. In 2009, a World Health Organization (WHO) study found that using a surgical checklist protocol in the intraoperative

1. Plastic surgeon at Hospital Israelita Albert Einstein and Instituto Dante Pazzanese de Cardiologia, São Paulo, SP, Brazil.

2. Plastic surgeon at Hospital Israelita Albert Einstein, São Paulo, SP, Brazil.

3. Cardiologist at Hospital Israelita Albert Einstein, São Paulo, SP, Brazil.

4. Anesthesiologist at Hospital Israelita Albert Einstein, São Paulo, SP, Brazil. 
period, based on a set of simple checklists to be used at various stages of surgery, significantly reduced the rate of complications ${ }^{1}$.

This paper reports the creation of a preoperative checklist for application in esthetic plastic surgeries.

\section{METHODS}

This checklist consists of 29 yes/no questions, one question ranking the risk of deep vein thrombosis, and four blank spaces to be filled in with specific information. The checklist is divided into three areas: anesthesia, psychological aspects, and clinical risk factors (Tables 1 to 3 ). There is also a list of information sources that are quickly and easily accessible by the physician via the Internet or by portable electronic devices such as the Iphone ${ }^{\circledR}$ or $\operatorname{Ipad}{ }^{\circledR}($ Table 4).
The answers are framed with colors that correspond to the level of surgical risk: green, irrelevant risk; blue, low risk; yellow, medium risk; and red, high risk (Table 5). These classifications were based on published scientific reports that identify risks and complications. This checklist is intended to be applied as the last step of the final preoperative visit.

\section{DISCUSSION}

The use of checklists has become increasingly common in different areas such as construction, gastronomy, aviation, and even finance. Especially in aviation, the use of checklists has been proven to be of extreme importance, and it is now an essential, mandatory procedure before flight commencement $^{2}$. Experience with the use of checklists in medicine is recent, and the preoperative stage checklist is the sole high-profile example. A simple list of questions

Table 1 - Anesthetic procedure.

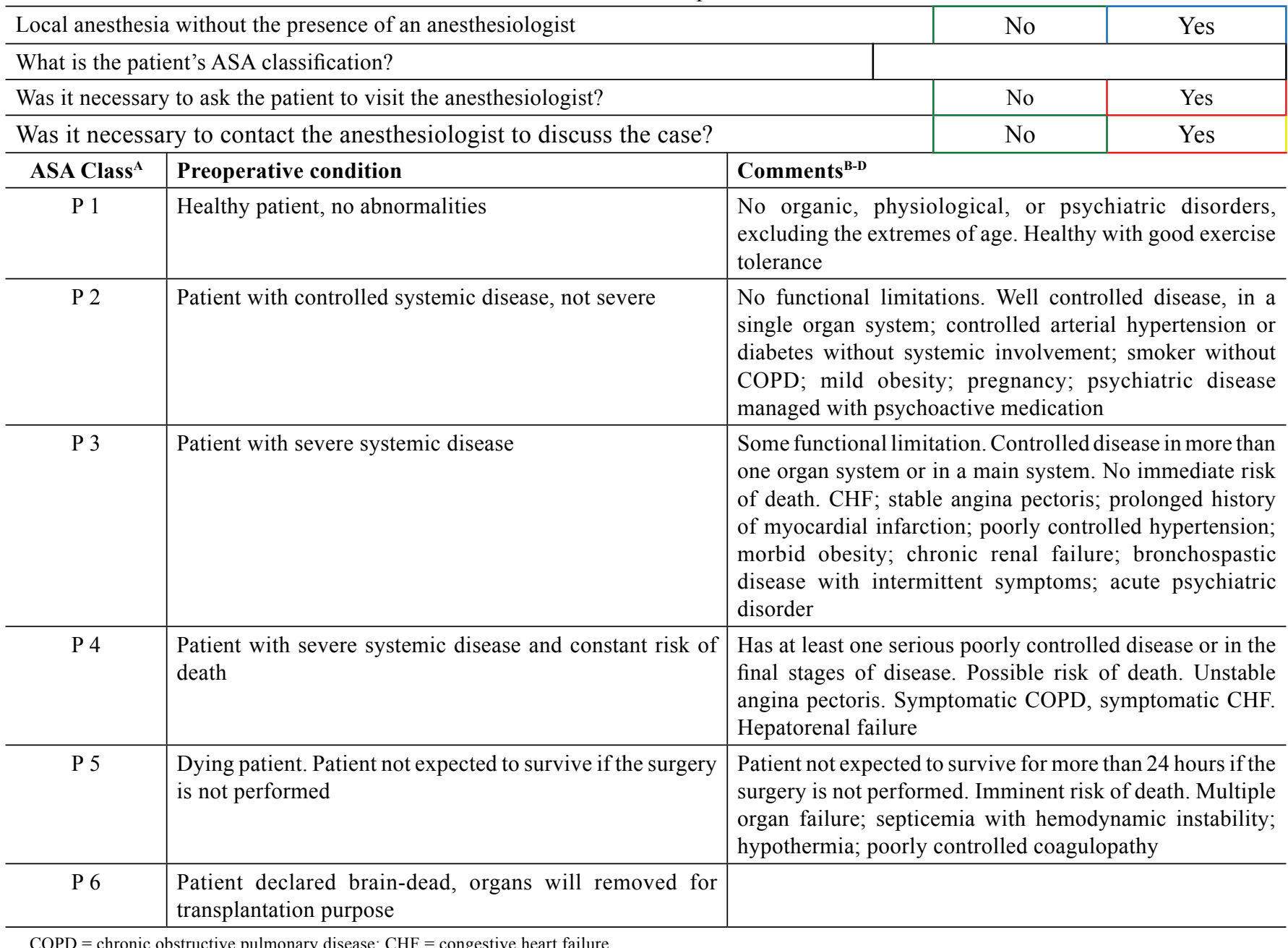

$\mathrm{COPD}=$ chronic obstructive pulmonary disease $\mathrm{CHF}=$ congestive heart failure 
Table 2 - Psychological aspects.

\begin{tabular}{|c|c|c|}
\hline Has the patient visited a psychiatrist or psychologist? & No & Yes \\
\hline Is the patient currently under psychiatric treatment? & No & Yes \\
\hline Has the patient received psychiatric treatment? & No & Yes \\
\hline Has the patient undergone psychotherapy? & No & Yes \\
\hline Is the patient currently receiving psychotherapy? & No & Yes \\
\hline Is the patient taking psychoactive medications? & No & Yes \\
\hline If yes, name the medications & & \\
\hline Could the medication used interfere in the surgery/anesthesia ${ }^{\mathrm{E}}$ ? & No & Yes \\
\hline Was it necessary to discuss the case with the psychiatrist? & No & Yes \\
\hline Was it necessary to request the psychiatrist's report? & No & Yes \\
\hline Has the patient attended the medical visit alone? & No & Yes \\
\hline Was it necessary to ask the patient to return for an additional visit with a companion? & No & Yes \\
\hline Is this the patient's first esthetic surgery? & No & Yes \\
\hline Has the patient had four (or more) visits with different plastic surgeons for the same surgery? & No & Yes \\
\hline Has the patient undergone other esthetic surgeries with other doctors? & No & Yes \\
\hline Does the patient consume alcohol (more than two glasses per day for men; one glass a day for women)? & No & Yes \\
\hline Does the patient use psychoactive drugs? & No & Yes \\
\hline
\end{tabular}

Table 3 - Clinical risk factors ${ }^{\mathrm{F}}$.

\begin{tabular}{|c|c|c|}
\hline \multirow{2}{*}{$\begin{array}{l}\text { Age }>70 \text { years old } \\
\text { Low functional capability ( } \leq 4 \text { METS: able to walk }<2 \text { blocks without stopping or has difficulty climbing a } \\
\text { flight of stairs) }\end{array}$} & No & Yes \\
\hline & No & Yes \\
\hline Systemic arterial hypertension without ventricular hypertrophy & No & Yes \\
\hline Insulin dependent diabetes mellitus & No & Yes \\
\hline $\mathrm{COPD}$ or $\mathrm{PO}_{2}<60 \mathrm{mmHg}$ or $\mathrm{PCO}_{2}>50 \mathrm{mmHg}$ & No & Yes \\
\hline Renal failure (creatinine $\geq 2.3 \mathrm{mg} / \mathrm{dl}$ ) & No & Yes \\
\hline Liver disease with MELD score $>14^{\mathrm{G}}$ & No & Yes \\
\hline $\begin{array}{l}\text { Active heart disease; valvular disease (mitral or aortic stenosis); arrhythmia; acute myocardial infarction within } \\
<6 \text { months; heart failure; acute pulmonary edema within }<1 \text { month }\end{array}$ & No & Yes \\
\hline Smoker & No & Yes \\
\hline Risk of deep vein thrombosis & Medium & High \\
\hline Is the patient taking medication that interferes with the surgery/anesthesia? & No & Yes \\
\hline \multicolumn{3}{|l|}{ If yes, name the medication } \\
\hline Allergy to medication or material (sutures or dressings) & No & Yes \\
\hline \multicolumn{3}{|l|}{ If yes, provide more details } \\
\hline
\end{tabular}

regarding how to identify the side of the body where the surgery will be performed resulted in a significant decrease in error rate ${ }^{1,2}$.

This paper presents a checklist to be used as a final review process after all routine aspects of surgical patient care have been completed. The physician answers the checklist questions and enters the appropriate data at the end of the last visit in order to identify possible oversights and reinforce the need to implement previously considered safety measures. The checklist items were chosen based on 
Table 4 - Sources of information.

\begin{tabular}{|c|c|c|}
\hline A & Internet & http://www.asahq.org/For-Members/Clinical-Information/ASA-Physical-Status-Classification-System.aspx \\
\hline B & Internet & http://my.clevelandclinic.org/services/anesthesia/hic_asa_physical_classification_system.aspx \\
\hline $\mathrm{C}$ & Iphone & Eponymus \\
\hline $\mathrm{D}$ & Iphone & http://www.whonamedit.com/azlist.cfm/x.html \\
\hline $\mathrm{E}$ & Iphone & Epocrates \\
\hline $\mathrm{F}$ & Internet & $\begin{array}{l}\text { Fleisher LA, Beckman JA, Brown KA, Calkins H, Chaikof EL, Fleischmann KE, et al. ACC/AHA } 2007 \text { Guidelines } \\
\text { on Perioperative Cardiovascular Evaluation and Care for Noncardiac Surgery: A Report of the American College of } \\
\text { Cardiology/American Heart Association Task Force on Practice Guidelines (Writing Committee to Revise the } 2002 \\
\text { Guidelines on Perioperative Cardiovascular Evaluation for Noncardiac Surgery) developed in collaboration with the } \\
\text { American Society of Echocardiography, American Society of Nuclear Cardiology, Heart Rhythm Society, Society of } \\
\text { Cardiovascular Anesthesiologists, Society for Cardiovascular Angiography and Interventions, Society for Vascular } \\
\text { Medicine and Biology, and Society for Vascular Surgery. J Am Coll Cardiol. 2007;50(17):e159-241. }\end{array}$ \\
\hline G & Internet & www.unos.org/resources/meldPeldCalculator.asp \\
\hline $\mathrm{H}$ & Internet & $\begin{array}{l}\text { Anger J, Baruzzi ACA, Knobel E. Um protocolo de prevenção de trombose venosa profunda em cirurgia plástica. } \\
\text { (A protocol for prevention of deep vein thrombosis in plastic surgery) Rev Soc Bras Cir Plást. 2003;18(1):47-54. } \\
\text { Available at: http://www.rbcp.org.br/detalhe_artigo.asp?id=351 }\end{array}$ \\
\hline I & Internet & $\begin{array}{l}\text { Young VL, Watson ME. The need for venous thromboembolism (VTE) prophylaxis in plastic surgery. Aesthet Surg } \\
\text { J. 2006;26(2):157-75. }\end{array}$ \\
\hline
\end{tabular}

\begin{tabular}{l|c}
\hline \multicolumn{2}{c}{ Table 5 - Attention criteria. } \\
\hline Criteria for attention: color \\
\hline Irrelevant risk & green \\
\hline Low risk & blue \\
\hline Medium risk & yellow \\
\hline High risk & red \\
\hline
\end{tabular}

adverse event reports and accumulated clinical and anesthetic experience.

The surgeon should assess and classify the risks surrounding the administration of anesthesia according to the criteria of the American Society for Anesthesiology (ASA) during the visiting process. This step is just a form of screening, since the final assessment of anesthetic risk will be performed by the anesthesiologist. In situations where the ranking is not ASA 1 or if questions about medications or allergies arise, preliminary assessment may ensure greater interaction with the anesthesiologist, either through oral communication or in person during the patient's pre-operative meeting with the anesthesiologist.

ASA ranking is limited to the contents of the column "Preoperative condition" in Table 1. To illustrate and facilitate the classification, the "comments" column was inserted for each level, based on the Cleveland Clinic report (Cleveland, OH, USA), with the addition of an item in the category ASA 2, which asks about active psychiatric treatment with psychopharmacological drugs. Psychiatric instability is considered an active disease ${ }^{3,4}$.
The questions contained in the section on psychological aspects are based on published articles. In 1998, Sarwer et al. ${ }^{5}$, prospectively analyzed 100 patients undergoing esthetic surgery and detected body dysmorphophobia in $7 \%$ of these individuals, a rate significantly higher than the $2 \%$ found by Andreasen and Bardach ${ }^{6}$ in a similar population. Hodgkinson ${ }^{7}$ stated that patients with previous plastic surgeries who are especially unhappy with the results may be suffering from body dysmorphophobia. The presence of a companion in the visit was considered necessary, since the patient often does not retain the information and explanations given by the physician ${ }^{8}$.

Current anesthetic techniques and clinical assessments enable the performance of surgeries with relative safety, so patients classified as ASA 2 can undergo surgeries considered of esthetic purpose. Table 3, which includes clinical risk factors, may be useful for the final review of these patients. Risk classification of deep vein thrombosis was based on a study by Anger et al. ${ }^{9}$ published in 2003 .

The large volume of scientific knowledge has always helped physicians, but it can also put them in difficult situations because it is impossible to know everything and be completely updated in all fields of medical practice. New medications and new treatments emerge every day. The list of information sources, presented in Table 4, is intended to enable fast access to relevant information during the patient's care. This list contains Internet portals and free software like Epocrates, which allow for quick information searches during medical visits. This access enables the identification and control of potential risks of 
medication used by patients, such as psychoactive drugs. Because of the increasing use of psychopharmacological drugs that can alter the administration of anesthesia or increase the risk of deep vein thrombosis, it is important for the physician to have current information about these medications.

Ranking answers by color corresponding to levels of risk aims to draw the surgeon's attention during the final assessment of each patient. Risk classification was based on medical literature data. We did not propose to quantify the risk associated with the resulting colors for each patient.

It has been well demonstrated in aviation that following a rigid checklist increases safety levels ${ }^{2}$. Obviously, accidents may still occur, and the introduction of new technologies and the evolution of older technologies necessitate constant reworking of the aviation checklist. Similarly, the preoperative checklist is flexible and can be adapted as practices change. The use of our checklist in a large series of patients should enable quantification and qualification of preventable failures.

\section{REFERENCES}

1. Haynes AB, Weiser TG, Berry WR, Lipsitz SR, Breizat AH, Dellinger EP, et al. Safe surgery saves lives study group. A surgical safety checklist to reduce morbidity and mortality in a global population. N Engl J Med. 2009;360(5):491-9.

2. Gawande A. The checklist manifesto: how to get things right. New York: Metropolitan Books; 2009.

3. American Society of Anesthesiologists. ASA Physical Status Classification System. Available at: http://www.asahq.org/For-Members/ClinicalInformation/ASA-Physical-Status-Classification-System.aspx. Access on: $1 / 11 / 2011$.

4. Cleveland Clinic. ASA Physical Classification System. Available at: http:// my.clevelandclinic.org/services/anesthesia/hic_asa_physical_classification_system.aspx. Access on: 1/11/2011.

5. Sarwer DB, Wadden TA, Pertschuk MJ, Whitaker LA. Body image dissatisfaction and body dysmorphic disorder in 100 cosmetic surgery patients. Plast Reconstr Surg. 1998;101(6):1644-9.

6. Andreasen NC, Bardach J. Dysmorphophobia: symptom or disease? Am J Psychiatry. 1977;134(6):673-6.

7. Hodgkinson DJ. Identifying the body-dysmorphic patient in aesthetic surgery. Aesthetic Plast Surg. 2005;29(6):503-9.

8. Godwin Y. Do they listen? A review of information retained by patients following consent for reduction mammaplasty. Br J Plast Surg. 2000;53(2):121-5.

9. Anger J, Baruzzi ACA, Knobel E. Um protocolo de prevenção de trombose venosa profunda em cirurgia plástica. (A protocol for prevention of deep vein thrombosis in plastic surgery) Rev Soc Bras Cir Plást. 2003;18(1):47-54

\section{Correspondence to:}

